\title{
Sobre ineditismo de idéias, citações de autores, marcas comerciais e patentes na Ortodontia
}

\author{
Alberto Consolaro \\ Professor Titular em Patologia Bucal pela Faculdade de Odontologia de Bauru - USP
}

O destaque acadêmico, o prestígio intelectual e a valorização profissional no mundo científico têm por base o ineditismo de uma idéia, que resulta em trabalhos científicos nas suas variadas modalidades como: cartas ao editor, pequenas comunicações, trabalhos originais, teses, livros, apresentações orais ou escritas em reuniões e congressos. Não devemos esquecer dois exemplos:

1) A molécula do DNA foi desvendada em um trabalho de uma página, sem nenhuma fotografia, com 5 referências bibliográficas, publicado na Europa pela revista Nature $^{6}$. O primeiro autor tinha 21 anos e o segundo 37, ambos ganharam o Prêmio Nobel de 1962;

2) A causa da tragédia dos milhares de pacientes com anomalias induzidas na década de 50 e 60, até então desconhecida, foi comunicada como sendo a talidomida, em uma carta ao editor enviada à revista Lancet por um médico australiano.

Quando o resultado inédito de um trabalho, idéia, técnica, instrumento ou aparelho, for apresentado em um evento científico como exposição oral ou painel, ou então publicado em forma de artigo, ou ainda como carta ao editor, significa que foi disponibilizado à sociedade para dele fazer uso, se assim achar oportuno, conveniente e/ou pertinente. Em outras palavras, desta forma, o resultado tornou-se público, para o uso público, de domínio público. Se a sociedade achar interessante pode fazer outros testes, novos trabalhos surgirão e críticas e sugestões serão geradas, o processo e a idéia melhorados. Quiçá, os resultados serão aplicados no mundo real da vida pessoal e social, fazendo parte da cadeia produtiva em que todos estão envolvidos, nesta forma capitalista de viver.

A vaidade, no sentido positivo da palavra, de um pesquisador, cientista, inventor, professor universitário e outros tipos de profissionais, está na possibilidade de ser reconhecido como o indivíduo, o cidadão, o único ou o primeiro a vir a público com aquela idéia e ter podido contribuir para a melhora do mundo. Afinal, são poucos os que conseguem esta proeza. Mesmo com a grande quantidade de trabalhos publicados, ainda são poucas as idéias inéditas, pertinentes e que realmente contribuem com o todo.

O número de citações de uma idéia, resultado ou observação equivale à dimensão do reconhecimento do que foi publicado, do que foi tornado público, do que foi oferecido à sociedade. Deste modo, o mundo científico vai desenvolvendo-se paralelamente ao mundo real. Por exemplo, Wilhelm Konrad Roentgen descobriu o raio-X, mas não requereu patente de seus aparelhos e nem mesmo registrou uma marca comercial para explorar suas observações e invenções. Nobel, por sua vez, patenteou e explorou comercialmente seus inventos, mas depois deixou a fortuna construída para a Academia Sueca de Ciências premiar os cientistas no mundo moderno, em várias áreas do conhecimento humano.

Não necessariamente o número de citações significa o reconhecimento de uma idéia, resultado ou observação inédita. A vaidade de ser muito citado na literatura não satisfaz a todos igualmente. Para alguns cientistas, pesquisadores e demais profissionais da área, ou para os seus financiadores, o reconhecimento advém de futuros benefícios fi- 
nanceiros, sociais e materiais, decorrentes do uso social, comercial e industrial daquela idéia inédita. Os financiadores podem ser investidores, empresas, universidades ou governos, com suas agências fomentadoras da pesquisa.

Para viabilizar o reconhecimento financeiro de uma idéia ou de um resultado inédito estabeleceram-se conceitos de propriedade intelectual, de propriedade industrial ou patentes, e de propriedade comercial ou marcas registradas.

O conceito de ética, segundo os especialistas no assunto, muda e evolui com o tempo e de forma diferente em cada sociedade. Na publicação de trabalhos parece lógico que devemos, geralmente nos primeiros parágrafos da introdução, explicar porque propomos realizar um determinado trabalho e quais foram as premissas daquela idéia, quem e o quê se publicou antes, quase como um respeito aos que antes trabalharam na mesma área ou assunto. Sem a história dos que fizeram antes, o presente fica solto, sem bases sólidas de argumentação e existência. Reconhecer o que já foi feito ou quem fez primeiro representa uma das práticas mais antigas e clássicas do mundo científico. Afinal a moeda que move o mundo científico, que dá prestígio, reconhecimento e até ajuda na obtenção de novos financiamentos para novos trabalhos, é a citação bibliográfica. A publicação de um trabalho inédito pode gerar ganhos materiais, mas indiretos e a longo prazo.

Se alguém desejar com seus inventos, idéias e observações ter ganhos financeiros e materiais deve ter outra prática antes de publicá-los: publicar implica em tornar público, dar ao público, ser da sociedade, de domínio e uso público. Só restarão citações bibliográficas, se houver ética, para se obter um grau de reconhecimento do trabalho.

Para se obter ganhos financeiros e materiais de seus inventos, idéias, modificações técnicas e observações, antes de torná-las públicas, deve-se registrálas, ou melhor, deve-se requerer patente. Antes de publicar deve-se obter a marca registrada do nome dado ao invento, dispositivo, técnica ou coisa parecida. Somente após a obtenção da patente e/ou da marca comercial se deve pensar em publicação, se assim se decidir. A publicação de dados, inventos e técnicas caracteriza a ciência; a exploração comercial e industrial de inventos, idéias e técnicas antes de publicar corresponde à prática da tecnologia. Existem, no governo brasileiro, institutos e órgãos que registram as patentes e marcas comerciais brasileiras, bem como isto se faz também em instituições internacionais que as registram no âmbito mundial. Este processo não é difícil e nem oneroso, embora haja lendas que dizem o contrário.

A Odontologia e, mais especificamente, a Ortodontia são muito técnicas e com muitos dispositivos e abordagens, aumentando a possibilidade de novos ou modificados instrumentos, dispositivos e formas de tratamento. Ao se ter novas idéias, ao se criar novos instrumentos, novas técnicas ou modificações, pergunte a você mesmo: quero obter ganhos materiais ou apenas ser citado por outros colegas pesquisadores como reconhecimento do que proporei? Se a resposta for que se quer apenas
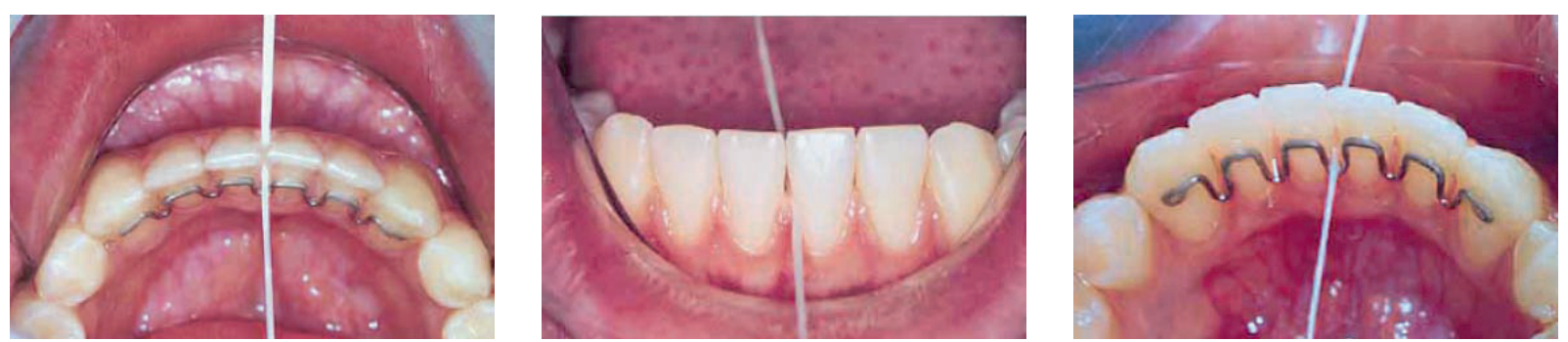

FIGURA 1 - Aspectos clínicos da "contenção de Lew4"estudada e aperfeiçoada por Bicalho e Bicalho', conforme demonstraram as três fotografias publicadas originalmente em seu trabalho de 2001 como figuras 10 a 12. 
publicar e ser citado, você estará na dependência da conduta de cada pesquisador em citá-lo ou não, e isto tem a ver com o exercício da ética.

Mas se quer reconhecimento além das citações bibliográficas, antes de publicar registre sua idéia, seu invento, sua modificação, mesmo que isto seja aparentemente insignificante ou comum. Entre as nações, os organismos ficam comparando quem tem mais marcas registradas e patentes e usam estes números para medir o grau de desenvolvimento de cada país.

Como exemplo do uso de citação bibliográfica, marca comercial e patente pode-se utilizar a forma de contenção fixa com livre acesso ao fio dental, utilizada por muitos profissionais em muitos pacientes. Ela foi descrita pela primeira vez por $\mathrm{Lew}^{4}$, da Universidade de Singapura, e publicada em janeiro de 1989, mas não se tem conhecimento se foi registrada ou patenteada; muito provavelmente não. O trabalho originalmente publicado no Journal of Clinical Orthodontics ${ }^{4}$ foi extremamente objetivo, incluindo em 2 páginas: três figuras, sendo uma do autor, outra de um esquema e uma terceira com situação clínica de uso da contenção modificada, mais três notas de rodapé e dez referências.

Posteriormente, outros autores publicaram casos com contenções semelhantes: Bicalho e Bicalho ${ }^{1}$ no
Brasil, em setembro/outubro de 2001; Cerny², em dezembro de 2001, um ortodontista clínico australiano; Costa et $\mathrm{al}^{3}$. em janeiro de 2005, também brasileiros. Shirasu et al. ${ }^{5}$, em janeiro/fevereiro de 2007, avaliaram comparativamente os efeitos periodontais da contenção fixa modificada com a convencional.

Se Lew ${ }^{4}$, em 1989, houvesse registrado patente e marca comercial, provavelmente estaríamos referindo-se à contenção fixa modificada como "contenção de Lew", um nome bastante oportuno, o que seria eticamente desejado, considerando que tudo leva à evidência de ser o pioneiro nesta modificação técnica. Também quando citada a modificação preconizada, se a marca comercial ou patente houvessem sido requeridas, deveríamos usar sobrescrito os símbolos ${ }^{\circledR}$ ou $^{\mathrm{TM}}$.

Se mais ousado, Lew poderia ter obtido lucro com sua patente, pois uma empresa comercializaria contenções pré-fabricadas pelo mundo todo, auferindo ganhos financeiros! Mas ele não pode ainda requerer patente ou marca comercial? Não! Sua idéia e modificação técnica são públicas a partir de sua publicação, não mais the pertencem, a não ser do ponto de vista histórico e ético.

Após a publicação é ciência, antes é tecnologia. Então, façamos nossas opções!

\section{REFERÊNCIAS}

1. BICALHO, J. S.; BICALHO, K. T. Descrição do método de contenção fixa com livre acesso ao fio dental. R Dental Press Ortodon Ortop Facial, Maringá, v. 6, n. 5, p. 97-104, set./out. 2001.

2. CERNY, R. Permanent fixed lingual retention. J Clin Orthod, Boulder, v. 35, p. 728-732, Dez. 2001.

3. COSTA, M. T.; LENZA, M. A.; BRITO, R. S. A. Bonding a V-loop lingual retainer with a duralay transfer tray. J Clin Orthod, Boulder, v. 39, no. 1, p. 44-46, Jan. 2005.
4. LEW, K. K. K. Direct-bonded lingual retainer. J Clin Orthod, Boulder, v. 23, no. 7, p. 490-491, Jul. 1989.

5. SHIRASU, B. K.; HAYACIBARA, R. M.; RAMOS, A. L. Comparação de parâmetros periodontais após utilização de contenção convencional 3×3 plana e contenção modificada. R Dental Press Ortodon Ortop Facial, Maringá, v. 12, n. 1, p. 41-7, jan/fev. 2007.

6. WATSON, J. D.; CRICK, F. H. C. Molecular structure of nucleic acids. Nature, London, no. 4356, p. 737, April 1953. 